\title{
Commentary: Complications rescue and long-term survival- Where do the Pillars of Hercules lie?
}

Amedeo Anselmi, MD, PhD, ${ }^{\mathrm{a}}$ and Alfonso Agnino, $\mathrm{MD}^{\mathrm{b}}$

The STICH trial and the associated substudies have provided a great deal of evidence about the effectiveness of coronary artery bypass grafting (CABG) in the treatment of ischemic cardiomyopathy. Nonetheless, they have also left several gaps in knowledge: for example, the relationship between complications and survival was analyzed at the 30th postoperative day only. ${ }^{1}$ Although it has been ascertained that patients with more depressed left ventricular ejection fraction (LVEF) will have worse late survival despite optimal surgical and/or medical management than will patients with normal left ventricular function, discussions have arisen regarding reasonable and unreasonable usage of human and social resources for the treatment of the most severely ill patients. These discussions are both clinical and ethical, and they appear every time the limits of contemporary medical knowledge, convictions, and health care system capacities are overwhelmed. The ongoing SARS-CoV-2 pandemic is painfully illustrating the reality of such aspects to both the medical community and the public. Similar to sailors of the ancient world, we face, in humility and grief, the pillars of Hercules marking the limits of our possibilities, only to ask whether and how we will be capable of pushing beyond them.

In that sense, one interpretation of the important and commendable work by Omer and colleagues ${ }^{2}$ consists of the idea that CABG recipients with a preoperative LVEF of $\leq 35 \%$ who have survived multiple severe postoperative

From the a Division of Thoracic and Cardiovascular Surgery, Pontchaillou University Hospital, Rennes, France; and ${ }^{\mathrm{b}}$ Division of Robotic and Minimally Invasive Cardiac Surgery, Cliniche Humanitas Gavazzeni, Bergamo, Italy.

Disclosures: Authors have nothing to disclose with regard to commercial support.

Received for publication March 31, 2020; revisions received March 31, 2020; accepted for publication March 31, 2020; available ahead of print April 11, 2020.

Address for reprints: Amedeo Anselmi, MD, PhD, Division of Thoracic and Cardiovascular Surgery, Pontchaillou University Hospital, Rennes 35000, France (E-mail: amedeo.anselmi@chu-rennes.fr).

J Thorac Cardiovasc Surg 2022;163:122-3

$0022-5223 / \$ 36.00$

Copyright (c) 2020 by The American Association for Thoracic Surgery

https://doi.org/10.1016/j.jtcvs.2020.03.123

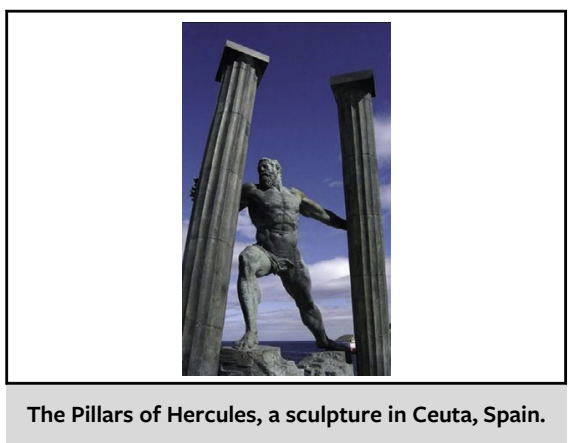

CENTRAL MESSAGE

The detrimental impact of mul-

tiple postoperative complica-

tions on late survival raises

clinical and ethical questions and

requires collective efforts to

overcome.

complications will experience worse outcomes at follow-up but that such outcomes will more likely result from their overall fragility and deconditioning after the complications themselves and the prolonged hospital and/or intensive care unit stay rather than to heart failure (LVEF being no more associated in a dose-dependent manner to the risk of late death). This is disturbing for health care providers who have devoted major efforts in the rescue of patients with the most severe postoperative course, which has intuitively been considered a success. ${ }^{3}$

The authors appropriately conclude that additional energies should be consecrated to the prevention of severe postoperative complications in this subset of patients; however, the current data provide few clues about how to pursue such a target. One must underline the importance of extreme vigilance of these patients in the early postoperative period and the promptness of escalating the level of care in response to a first major complication to prevent additional complications from occurring (the "domino" effect). Beyond that, more granular strategies can hardly emerge. The Veterans Affairs Surgical Quality Improvement Program database is a tremendous resource of valuable information; however, the report by Omer and colleagues ${ }^{2}$ lacks potentially significant data, such as the surgical technique (beating-heart onpump CABG has been proposed for very depressed LVEF or active ischemia); the number and outcomes of patients later undergoing heart transplantation or left ventricular assist device implantation (and their interaction with the complications burden); and the demonstration and extent of 
myocardial viability. In this respect, it is surprising that late myocardial recovery has been scarcely investigated in prospective studies, ${ }^{4}$ although it constitutes one theoretical legitimation of the current indications for CABG. Other limitations are of minor import, such as the $99 \%$ prevalence of male patients, one of the STICH substudies having demonstrated the absence of gender-related differences in the late outcomes among these patients. ${ }^{5}$ Perhaps the greatest value of the study by Omer and colleagues ${ }^{2}$ does not lie in the questions it answers, but in those it (re)opens, as well as the troubled times we are experiencing.

\section{References}

1. Wrobel K, Stevens SR, Jones RH, Selzman CH, Lamy A, Beaver TM, et al. Influence of baseline characteristics, operative conduct, and postoper- ative course on 30-day outcomes of coronary artery bypass grafting among patients with left ventricular dysfunction: results from the Surgical Treatment for Ischemic Heart Failure (STICH) trial. Circulation. 2015;132: 720-30.

2. Omer S, Adeseye A, Jimenez E, Cornwell L, Massarweh N. Low left ven tricular ejection fraction, complication rescue, and long-term survival after coronary artery bypass grafting. J Thorac Cardiovasc Surg. 2022;163: 111-9.e2.

3. Gaudino M, Girola F, Piscitelli M, Martinelli L, Anselmi A, Della Vella C, et al Long-term survival and quality of life of patients with prolonged postoperative intensive care unit stay: unmasking an apparent success. J Thorac Cardiovasc Surg. 2007; 134:465-9.

4. Panza JA, Ellis AM, Al-Khalidi HR, Holly TA, Berman DS, Oh JK, et al. Myocardial viability and long-term outcomes in ischemic cardiomyopathy. $N$ Engl J Med. 2019;381:739-48.

5. Piña IL, Zheng Q, She L, Szwed H, Lang IM, Farsky PS, et al. Sex difference in patients with ischemic heart failure undergoing surgical revascularization: results from the STICH trial (Surgical Treatment for Ischemic Heart Failure). Circulation. 2018;137:771-80 